\title{
Social Appearance Anxiety and Rosenberg Self-esteem Scores in Young Physical Disabled Athletes
}

\author{
Havva Demirel \\ Faculty of Sport Sciences, Selçuk University, Turkey
}

Copyright $\subseteq 2019$ by authors, all rights reserved. Authors agree that this article remains permanently open access under the terms of the Creative Commons Attribution License 4.0 International License

\begin{abstract}
Introduction: The social appearance anxiety is defined as tension and anxiety experienced by people when they are assessed by others in terms of their physical appearance and self-esteem is defined as feelings of one's personal self-worth, reflecting person's evaluation of his or her own worth. Aim: This study was conducted to investigate the differences in social appearance anxiety and self-esteem scores in physical disabled athletes and non-disabled athletes. Materials and Methods: One hundred and forty-eight physical disabled athletes and 60 non-disabled athletes participated in the study. The Turkish versions of the Social Appearance Anxiety Scale and Rosenberg Self-Esteem scale was used to assess the points associated with social appearance anxiety and self-esteem. Results: Disabled athletes had higher self-esteem and social appearance anxiety scores compared to non-disabled athletes. Also, disabled athletes having medal had decreased self-esteem and social appearance anxiety scores compared to disabled athletes not having medal. These results suggest that physical activity can improve mental health in especially successful athletes. Also, the self-esteem scores had positive correlation with the social appearance anxiety score in total sample, as well as in disabled athletes and non-disabled athletes. Conclusion: The higher self-esteem and social appearance anxiety scores in disabled athletes may be related to the higher depression, anxiety and psychological stress in athletes compared to non-athletes. These results suggest that physical activity can improve mental health in only top successful athletes.
\end{abstract}

Keywords Self-esteem, Social Appearance Anxiety, Disability, Athlete

\section{Introduction}

Social appearance anxiety is defined as outwardly apparent anxiety and tension, visibly accessible by others [1]. Beyond physical appearance, social appearance anxiety is similar to general social anxiety such that overall assessments related to general appearance of an individual are also indications [2]. Thus, literature suggests that social appearance anxiety is associated with body image [3] and self-esteem. Given that during the adolescence period assessment of physical appearance reinforces anxiety, social appearance anxiety is thought to be most intense and apparent during adolescence [4].

Self-esteem is strongly associated with social appearance anxiety. Both constructs demonstrate an individual's evaluation of his or her own worth [5]. Whereas self-esteem is related to self-worth, self-concept is closely related; both are indelible constructs when considering a person's mental health $[8,9]$. Self-concept is defined as what a person thinks about themselves. This definition is based on a person's own perceptions [6, 7]. Increased self-esteem and self-concept are viewed essential to education interventions. Indeed, self-concept has been shown to mediate academic achievement [10].

The relations of sport with social appearance anxiety and self-esteem have not been unequivocally established in young disabled and non-disabled athletes up to now. To this end, this study was conducted to investigate the differences in social appearance anxiety and self-esteem scores in young disabled and non-disabled athletes.

\section{Methods}

\subsection{Ethical Statement}

This study was performed in accordance with the Declaration of Helsinki and approved by the Local Committee for Medical Research Ethics.

\subsection{Subjects}

One hundred and forty-eight disabled athletes (107 men, mean age $=24.23$ years, $\mathrm{SD}=1.82 ; 41$ women, mean age $=$ 25.09 years, $\mathrm{SD}=2.31)$ and 60 non-disabled athletes $(40$ men, mean age $=25.44$ years, $\mathrm{SD}=2.61 ; 20$ women, mean 
age $=23.38$ years, $\mathrm{SD}=1.73$ ) participated in this study. Data were collected from disabled athletes of Turkey Disabled Sport Federation when they were in preparation camp to Europe Championship. Some of the data were collected during Ankarada amputee soccer team of Turkey Cup matches. In another part, the physically handicapped were collected during swimming races. Only physical disabled athletes were included the study. Non-disabled athletes were professional players of the different sport agencies in Konya, Turkey. All subjects were voluntaries to attend the study. All participants signed informed consents after the aims and objectives of the study have been clearly explained.

Exclusion criteria were health problems such as psychiatric, respiratory, metabolic, cardiac, or autonomic nervous system diseases that might change the self-esteem scale and social appearance anxiety scale scores.

\subsection{Self-esteem and Social Appearance Anxiety Scale Assessment}

The Turkish version [11] of the Social Appearance Anxiety Scale [Hart] was used to assess the points associated with social comparison scale[12].The Turkish version [13] of Self-Esteem Scale[14] was used to assess the points associated with self-esteem.

\subsection{Statistical Analysis}

Measured values are given as a mean +/- standard deviation. Statistical analysis was performed using Statistical Package for the Social Sciences (SPSS) for Windows (version 16.0)(SPSS Inc., Chicago, IL, USA). Student's t test, one way ANOVA and Pearson correlation tests were used to compare the self-esteem scale and social appearance anxiety scale scores in disabled and non-disabled athletes. A value of $\mathrm{p}<0.05$ was considered significant.

\section{Results}

Disabled athletes had statistically significant higher self-esteem and social appearance anxiety scores compared to non-disabled athletes (self-esteem score: $t=14.09$, $\mathrm{p}=0.00$; social appearance anxiety score: $\mathrm{t}=3.74, \mathrm{p}=0.00$ ) (Table 1). Kind of disability including physical disability, blindness, and deafness had no significant effect on self-esteem and social appearance anxiety scores.

There was a statistically significant Pearson correlation between self-esteem scale and social appearance anxiety scale in total sample $(\mathrm{r}=0.54, \mathrm{p}=0.00)$, as well as in disabled athletes $(\mathrm{r}=0.61, \mathrm{p}=0.00)$ and in non-disabled athletes $(\mathrm{r}=0.34, \mathrm{p}=0.007)$.

There was a sex related statistically significant different in disabled athletes in terms of both self-esteem score and social appearance anxiety score (self-esteem score: $\mathrm{t}=2.23$, $\mathrm{p}=0.04$; social appearance anxiety score: $\mathrm{t}=2.17, \mathrm{p}=0.04$ ), but not in non-disabled athletes (Table 2).

Table 1. Differences between disabled and non-disabled athletes in terms of social appearance anxiety and self-esteem scores

\begin{tabular}{|c|c|c|c|c|}
\hline & Disabled Athletes $(\mathbf{N}=\mathbf{1 4 8})$ & Non-disabled Athletes $(\mathbf{N}=\mathbf{6 0})$ & $\mathbf{T}$ & $\mathbf{P}$ \\
\hline Social Appearance Anxiety Score & $55.55 \pm 7.47$ & $51.65 \pm 4.82$ & 3.74 & 0.00 \\
\hline Self-Esteem Score & $55.69 \pm 10.34$ & $31.73 \pm 12.81$ & 14.09 & 0.00 \\
\hline
\end{tabular}

Table 2. Sex differences in disabled and non-disabled athletes in terms of social appearance anxiety and self-esteem scores.

\begin{tabular}{|c|c|c|c|c|}
\hline \multicolumn{5}{|c|}{ Disabled Athletes } \\
\hline & $\operatorname{Men}(N=107)$ & Women $(\mathrm{N}=41)$ & $\mathbf{t}$ & $\mathbf{p}$ \\
\hline Social Appearance Anxiety Score & $54.86 \pm 7.36$ & $57.34 \pm 7.55$ & 2.17 & 0.04 \\
\hline Self-Esteem Score & $54.56 \pm 10.93$ & $58.63 \pm 8.04$ & 2.23 & 0.04 \\
\hline \multicolumn{5}{|c|}{ Non-disabled Athletes } \\
\hline & $\operatorname{Men}(\mathrm{N}=40)$ & Women $(\mathrm{N}=\mathbf{2 0})$ & $\mathbf{t}$ & $\mathbf{p}$ \\
\hline Social Appearance Anxiety Score & $52.3 \pm 5.37$ & $50.63 \pm 3$ & 1.26 & 0.21 \\
\hline Self-Esteem Score & $33 \pm 12.76$ & $29.58 \pm 13.09$ & 0.95 & 0.34 \\
\hline
\end{tabular}

Table 3. Effect of age on social appearance anxiety and self-esteem scores in disabled athletes

\begin{tabular}{|c|c|c|c|}
\hline Age Interval & $\mathbf{N}$ & Social Appearance Anxiety Score & Self-Esteem Score \\
\hline $\mathbf{1 9 - 2 1}$ years & 47 & $52.28 \pm 12.33$ & $54.96 \pm 7.67$ \\
\hline $\mathbf{2 2 - 2 4}$ years & 60 & $57.82 \pm 9.17$ & $56.78 \pm 7.85$ \\
\hline $\mathbf{2 5 - 2 7}$ years & 20 & $59.6 \pm 10.03$ & $57.35 \pm 7.75$ \\
\hline $\mathbf{2 8 - 3 0}$ & 21 & $53.52 \pm 5.64$ & $51.62 \pm 5.65$ \\
\hline
\end{tabular}


Table 3 shows the effects of age on self-esteem and social appearance anxiety scores in disabled athletes. As the age increases, scores of self-esteem and social appearance anxiety were increasing significantly (self-esteem score: $\mathrm{F}=3.65, \mathrm{p}=0.01$; social appearance anxiety: $\mathrm{F}=9.84, \mathrm{p}=0.00$ ). But, there is no statistical significance in non-disabled athletes.

There were no statistically significant differences between married and single athletes in both disabled and non-disabled athletes in terms of self-esteem and social appearance anxiety scores. Also, there were no statistically significant difference between athletes playing individually and athletes playing a team sport in both disabled and non-disabled athletes in terms of self-esteem and social appearance anxiety scores.

Of 148 disabled athletes, 40 were a medal holder from national or international championships. Disabled athletes having medal had decreased self-esteem and social appearance anxiety scores compared to disabled athletes not having medal (self-esteem score: $\mathrm{t}=2.29, \mathrm{p}=0.04$; social appearance anxiety score: $\mathrm{t}=3.04, \mathrm{p}=0.003$ ).

\section{Discussion}

Due to their $20 \%$ prevalence in adolescents globally, mental health concerns are a vast health burden $[15,16]$. In attempts to alleviate this burden and search for variables that may hinder the high prevalence of mental health issues, researchers have demonstrated that physical activity has physical and psychological benefits $[17,18]$. In addition to benefits on cardiovascular disease, diabetes, hypertension, cancer, osteoporosis, and obesity [19-21], the positive effect of physical activity on mental health has been demonstrated in individuals with depression, anxiety, self-esteem, self-concept, anger, stress, and executive functioning concerns [22-24].

Literature increasingly suggests that disabled athletes experience higher alexithymia compared to disabled non-athletes $[25,26]$. In addition, alexithymia positively correlates with the social comparison score [27], and is related to higher depression, anxiety, and psychological stress [28, 29]. The relation between alexithymia and negative psychological correlates are only present in disabled athletes and not in non-athletes. Associations between alexithymia and mental health issues such as depression, anxiety, somatic and neurological disorders such as hypertension, Parkinson's disease, multiple sclerosis, and diabetes mellitus have previously been established [30, 31].

In the present study, disabled athletes had higher self-esteem and social appearance anxiety scores compared to non-disabled athletes. In addition, disabled athletes with medals had lower self-esteem and social appearance anxiety scores compared to disabled athletes without a medal. Thus, physical activity can improve mental health in only high achieving athletes [21-24].

\section{REFERENCES}

[1] Hart, E. A., M. R. Leary, and W. J. Rejeski. (1989). The measurement of social physique anxiety. Journal of Sport \& Exercise Psychology 11 (1): 94-104.

[2] White, E.K. (2008). The role of social physique anxiety and social appearance anxiety in the body checking behaviors of male and female college students. Unpublished Master Thesis. University of Nevada, Department of Psychology.

[3] Claes, L., Hart, T. A., Smits, D., Van Den Eynde, F., Mueller, A., Mitchell, J. E. (2012). Validation of the social appearance anxiety scale in female eating disorder patients. European Eating Disorders Review 20 (5): 406-409.

[4] Gümüş, A. E. (2000). Üniversite öğrencilerinin yalnızlık ve beden imgelerinden doyum sosyal kaygı düzeyleri ile ilişkisinin incelenmesi. Ankara Üniversitesi Eğitim Bilimleri Fakültesi Dergisi 33 (1): 99-108.

[5] Crocker J, Major B. Social stigma and self-esteem: The self-protective properties of stigma. Psychol Rev. 1989; 96: 608-630.

[6] Campbell JD. Self-esteem and clarity of the self-concept. J PersSoc Psychol. 1990; 59: 538-549.

[7] Rosenberg M. Self-concept and psychological well-being in adolescence. The development of the self. New York: Academic Press; 1985. pp. 205-246.

[8] Baumeister RF. The Self. In: Gilbert D., Fiske S., Lindzey G., editors. The handbook of social psychology. New York: Random House; 1998. pp.680-740.

[9] Shavelson RJ, Hubner JJ, Stanton GC. Self-concept: Validation of construct interpretations. Rev Educat Res. 1976; 46: 407-441.

[10] Marsh HW. A multidimensional, hierarchical model of self-concept: Theoretical and empirical justification. Educat Psychol Rev. 1990; 2: 77-172.

[11] Doğan T. Adaptation of the social appearance anxiety scale (saas) to Turkish: a validity and reliability study. (H. U. Journal of Education) 39: 151-159 [2010].

[12] Hart TA, Flora DB, Palyo SA, Fresco DM, Holle C, Heimberg RG. Development and examination of the social appearance anxiety scale. Assessment, Volume 15, No. 1, March 2008 48-59.

[13] Doğan T. Two-dimensional self-esteem: adaptation of the self-liking/self-competence scale into Turkish: a validity and reliability study. Education and Science2011, Vol. 36 (162): 126-137.

[14] Tafarodi, R. W., \& Swan, W. B. (2001). Two-dimensional self-esteem: Theory and measurement. Personality and Individual Differences, 31, 653-673.

[15] Atlas WHO. Child and adolescent mental health resources: global concerns, implications for the future. Geneva, Switzerland: World Health Organization; 2005. 
[16] Belfer ML. Child and adolescent mental disorders: the magnitude of the problem across the globe. J Child Psychol Psyc. 2008; 49: 226-236.

[17] Brown HE, Pearson N, Braithwaite RE, Brown WJ, Biddle SJ. Physical activity interventions and depression in children and adolescents. Sports Med. 2013; 43: 195-206.

[18] Dishman RK, Hales DP, Pfeiffer KA, Felton G, Saunders R, Ward DS, et al. Physical self-concept and self-esteem mediate cross-sectional relations of physical activity and sport participation with depression symptoms among adolescent girls. Health Psychol. 2006; 25: 396-407.

[19] Schranz N, Tomkinson G, Parletta N, Petkov O, Olds T. Can resistance training change the strength, body composition and self-concept of overweight and obese adolescent males? A randomised controlled trial. Br J Sports Med. 2014; 48: $1482-1488$.

[20] Buffart LM, Singh AS, van Loon EC, Vermeulen HI, Brug J, Chinapaw MJ. Physical activity and the risk of developing lung cancer among smokers: A meta-analysis. J Sci Med Sport. 2014; 17: 67-71.

[21] Penedo FJ, Dahn JR. Exercise and well-being: a review of mental and physical health benefits associated with physical activity. Curr Opin Psychiatr. 2005; 18: 189-193.

[22] Hassmén P, Koivula N, Uutela A. Physical exercise and psychological well-being: a population study in Finland. Prev Med. 2000; 30: 17-25.

[23] Davis CL, Tomporowski PD, McDowell JE, Austin BP, Miller PH, Yanasak NE, et al. Exercise improves executive function and achievement and alters brain activation in overweight children: a randomized, controlled trial. Health Psychol. 2011; 30: 91-98.

[24] Holley J, Crone D, Tyson P, Lovell G. The effects of physical activity on psychological well - being for those with schizophrenia: A systematic review. Br J Clin Psychol. 2011; 50: 84-105.

[25] Barlow M, Woodman T, Chapman C, Milton M, Stone D, Dodds T, Allen B. Who takes risks in high-risk sport?: the role of alexithymia. J Sport ExercPsychol 2015; 37(1):83-96.

[26] Misterska E, Glowacki M, Adamczyk K, Glowacki J, Harasymczuk J. A longitudinal study of alexithymia in relation to physical activity in adolescent females with scoliosis subjected to cheneau brace treatment: preliminary report. Spine 2014; 39(17):E1026-34.

[27] Demir H. Disabled athletes have higher alexithymia scores compared to disabled non-athletes. Journal of Research in Medical and Dental Science 2018, Volume 6, Issue 5, Page No: 302-304.

[28] Demirel H. Have University sport students higher scores depression, anxiety and psychological stress? Int J Environ SciEduc 2016; 11(16):9422-9425.

[29] Poquérusse J, Pastore L, Dellantonio S, and Esposito G. Alexithymia and autism spectrum disorder: a complex relationship. Front Psychol 2018; 9:1196.

[30] Karukivi M, Saarijärvi S. Development of alexithymic personality features. World J Psychiatry 2014; 4(4): 91-102.
[31] Ricciardi L, Demartini B, Fotopoulou A, Edwards MJ. Alexithymia in neurological disease: a review. J Neuropsychiatry Clin Neurosci 2015; 27:179-187. 